\title{
Uterine Lipoleiomyoma: a rare variant of benign uterine neoplasm
}

\author{
Sunil V. Jagtap*, Abhijit Phalke, Nitin S. Kshirsagar, Shubham S. Jagtap, Nitesh Nasre
}

Department of Pathology and Obstetrics and Gynecology, Krishna Institute of Medical Sciences, DTBU, Karad, Maharashtra, India

Received: 16 March 2019

Accepted: 04 May 2019

\section{*Correspondence:}

Dr. Sunil V. Jagtap,

E-mail: drsvjagtap@gmail.com

Copyright: (c) the author(s), publisher and licensee Medip Academy. This is an open-access article distributed under the terms of the Creative Commons Attribution Non-Commercial License, which permits unrestricted non-commercial use, distribution, and reproduction in any medium, provided the original work is properly cited.

\begin{abstract}
The lipomatous tumors are very rare benign neoplasms of the uterus. Lipoleiomyoma is a benign tumor which is variant of leiomyoma. It has similar clinical course and presentation like uterine leiomyoma and is typically found in postmenopausal women. Authors report a case of 45 years female presented with a complaint of increased frequency of menstrual cycles and generalized weakness since 5- 6 months. On ultrasonography abdomen - pelvis a single large lobulated hyperechoic mass was noted in the fundal myometrium measuring $5 \times 4.6 \mathrm{~cm}$. The finding was suggestive of fibroid uterus. On histopathological examination showed variable proportions of lobules of mature adipocytes and interlacing bundles of benign smooth muscle cells which was diagnostic of lipoleiomyoma. Authors are presenting this case for its rarity, clinical presentation, imaging and histopathological finding with differential diagnosis.
\end{abstract}

Keywords: Benign pelvic tumors, Histopathology lipoleiomyoma, Leiomyomas, Uterine tumors, Uterine tumors

\section{INTRODUCTION}

The lipomatous tumors of the uterus include a spectrum of lesions consisting of pure lipomas, lipoleiomyomas and fibromyolipoma. Lipoleiomyoma is a rare benign variant of leiomyoma having incidence of $0.03-0.2 \% .^{1,2}$ These tumors are variants of conventional leiomyomas, these tumors are having favorable prognosis. These patients may present with non-specific clinical manifestations

On imaging techniques, it is difficult to diagnose. The histopathological diagnosis plays important role and exclude the other differential diagnosis of various benign uterine neoplasms.

The awareness of this histopathological varient, its clinical presentation, and imaging features are important to avoid unnecessary surgeries as it has an excellent prognosis.

\section{CASE REPORT}

A 45 years female patient P2 L2 A0, presented with complaints of increased frequency of menstrual cycles and generalized weakness since 5-6 months. Her haemoglobin was $6.5 \mathrm{gm} \%$ and peripheral blood smear showed microcytic hypochromic anaemia. She was having hypothyroidism and on treatment. Her thyroid function test showed Free T3-1.7 nmol/lit, T4-5.8 $\mathrm{nmol} / \mathrm{lit}$ and serum TSH concentration - $65.08 \mathrm{mIU} / \mathrm{ml}$. On USG reported as uterus was bulky, retroverted and measured $9 \times 6.1 \times 5.5 \mathrm{~cm}$. A lobulated hyperechoic mass lesion was noted in the fundal myometrium measuring 5 $\mathrm{x} 4.6 \mathrm{~cm}$. The finding suggestive of fibroid uterus. The panhysterectomy was performed. The uterus was bulky and weighing 230 grams. On cut open endometrial canal showed a single large pedunculated mass arising from fundus. The mass measures $7.5 \times 5.5 \times 4 \mathrm{~cm}$. Cut section of mass was yellowish- grey, fleshy with tiny areas of hemorrhage and necrosis (Figure 1). On histological 
examination showed a tumor composed of mixture of benign smooth muscle cells and evenly distributed mature adipose tissue arranged in lobules and sheets. (Figure 2,3,4) There was no evidence of any atypia or malignant changes. On histopathology reported as uterine lipoleiomyoma. The cervix, endometrium, bilateral fallopian tubes and ovaries were unremarkable.

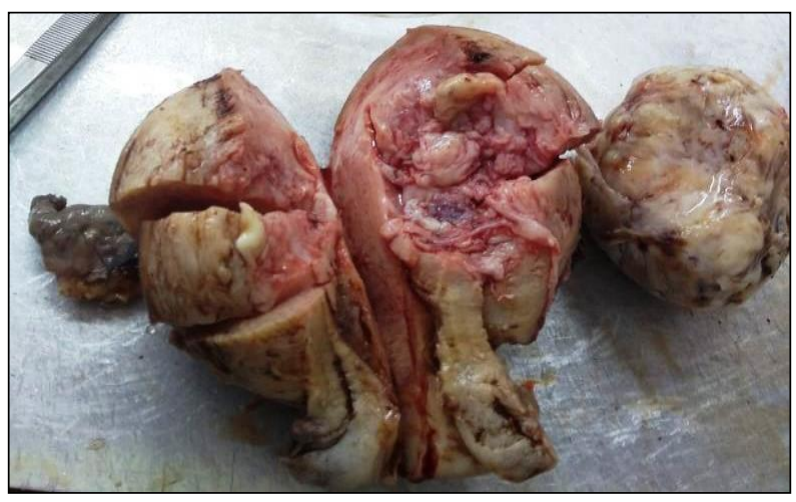

Figure 1: A panhysterectomy specimen on cut open endometrial canal: single large pedunculated mass arising from fundus. The mass measures $7.5 \times 5.5 \times 4 \mathrm{cms}$. Cut section of mass was yellowish- grey, fleshy with tiny areas of hemorrhage and necrosis.

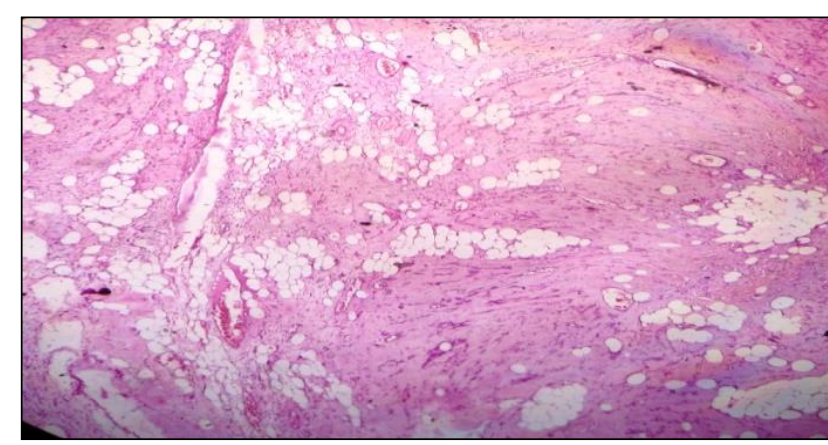

Figure 2: Tumor composed of mixture of benign smooth muscle cells and evenly distributed mature adipose tissue arranged in lobules and sheets. (haematoxyline and eosin stain, 40x)

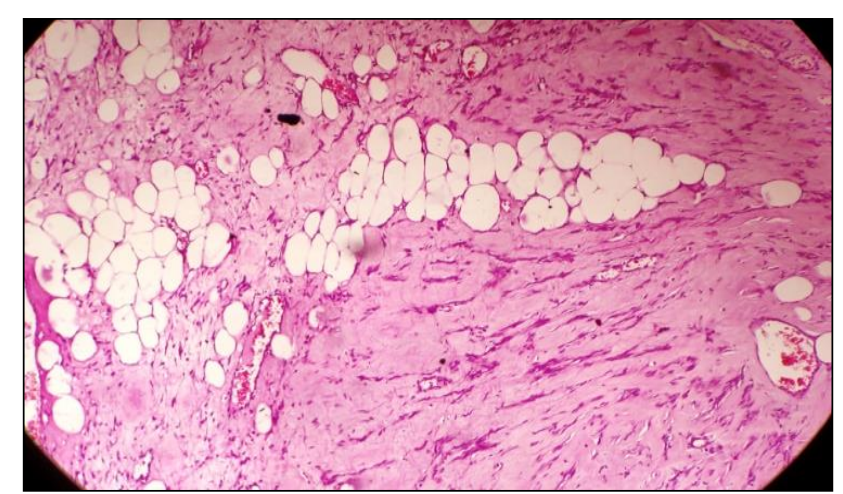

Figure 3: Tumor composed of mixture of benign smooth muscle cells and evenly distributed mature adipose tissue arranged in lobules and sheets. (haematoxyline and eosin stain, 40x).

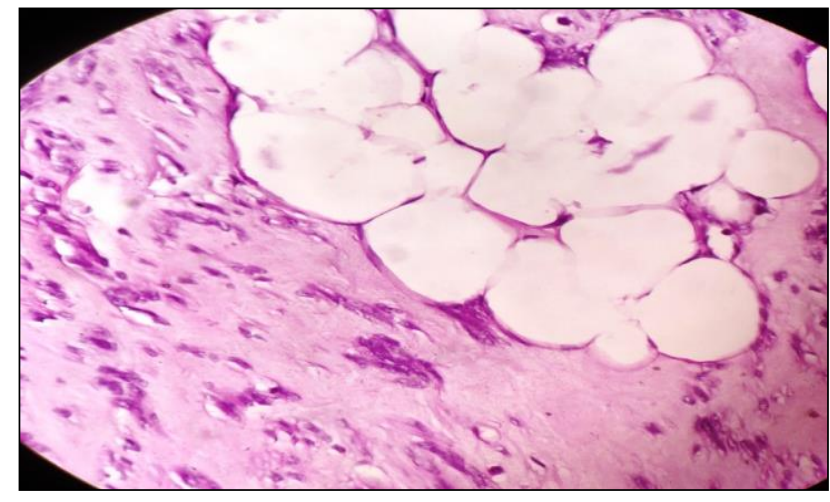

Figure 4: Tumor composed of mixture of benign smooth muscle cells and evenly distributed mature adipose tissue arranged in lobules and sheets. (haematoxyline \& eosin stain, 100x).

\section{DISCUSSION}

Lipoleiomyoma are rare benign tumor, which can occur anywhere in uterine corpus, cervix, retroperitoneum, ovaries and broad ligament. ${ }^{3}$ The occurrence of uterine lipoleiomyoma is extremely rare. These lesions frequently pose a diagnostic challenge for the clinician radiologists and pathologists. These tumors are usuall noted in post-menopausal women. ${ }^{5}$ Most cases of lipoleiomyomas are in of post or perimenopausal females while conventional leiomyomas are known to occur in women of reproductive age group and may regress after menopause. Clinically most of them are asymptomatic. The variable symptoms like pelvic pain, heaviness, lower abdominal fullness, discomfort, abnormal vaginal bleeding etc are noted. ${ }^{3,6}$ Lipoleiomyoma may be an incidental finding. ${ }^{7}$

In present case she was presented with complaints of increased frequency of menstrual cycles and generalized weakness since 5- 6 months.

Preoperative imaging can play an important role in determining the intrauterine location and fatty nature and any transformation of lipoleiomyoma Mostly the lipoleiomyomas are intramural in location, but their welldefined lobular mass can be localized at submucosal or subserosal site.

On USG imaging these tumors show well defined hyperechoic lesions with peripheral hypoechoic rim related to myometrium. On colour doppler shows low vascularity. However, finding may be non-specific. In present case. lobulated hyperechoic lesion in the fundal myometrium measuring $5 \times 4.6 \mathrm{~cm}$ was noted. The finding suggestive of fibroid uterus. While MRI study in such cases can be a modality of final diagnosis which shows hyperintense on TI with hypointense rim. ${ }^{8}$

The differential diagnosis for pelvic lipid tumors are lipoma, degenerative leiomyoma, hamartoma, pelvic fibromatosis, angiomyolipoma, carcinosarcoma with 
heterologous liposarcomatous differentiation cystic ovarian teratoma, low grade liposarcoma etc. ${ }^{6,9,10} \mathrm{~A}$ meticulous review of histomorphology can help in differentiating these lesions and is important to exclude malignant counterpart.

The histogenesis of lipoleiomyoma is of variable theories proposed as pluripotent migration, fatty degeneration, fatty infiltration, lipoblastic differentiation, metaplastic, hypoestrogenic state. ${ }^{3}$

Uterine lipoleiomyomas are known to have some metabolic disorders like hyperlipidemia, hypothyroidism, diabetes mellitus etc are associated with it. In present case patient was having hypothyroidism.

Only few reports describe giant lipoleiomyoma and often masquerade as malignant neoplasm. ${ }^{11}$ Lipoleiomyomas when clinically asymptomatic require no treatment. The treatment is usually surgical for symptomatic patient and patient with large masses, in the form of hysterectomy, myomectomy, tumor embolization etc. The asymptomatic lipoleiomyoma can be managed conservatively. The lipoleiomyomas are benign tumors of the uterus that have good prognosis and that do not directly affect mortality.

\section{CONCLUSION}

Lipoleimyoma is rare benign uterine neoplasm. The histopathological examination plays important role in diagnosis and guide for further management of these case.

Funding: No funding sources

Conflict of interest: None declared

Ethical approval: Not required

\section{REFERENCES}

1. Aung T, Goto M, Nomoto M, Kitajima S, Douchi T, Yoshinaga $\mathrm{M}$, et al. Uterine lipoleiomyoma: a histopathological review of 17 cases. Pathol Int. 2004;54:751-8.

2. Bindra R, Sharma N. Uterine lipoleiomyoma. Int $\mathbf{J}$ Gynaecol Obstet. 2010;12:2.

3. Akbulut M, Gündogan M, Yörükoglu A. Clinical and pathological features of lipoleiomyoma of the uterine corpus: a review of 76 cases. Balkan Med J. 2014;31:224-9.

4. Oh SR, Cho YJ, Han M, Bae JW, Park JW, Rha SH. Uterine Lipoleiomyoma in Peri or Postmenopausal Women. J Menopausal Med. 2015;21(3):165-70.

5. Manjunatha HK, Ramaswamy AS, Kumar BS, Kumar SP, Krishna L. Lipoleiomyoma of uterus in a postmenopausal woman. J Mid-life Heal. 2010;(2):86-8.

6. Kumar S, Garg S, Rana P, Hasija S, Prakash SK, Sen R. Lipoleiomyoma of uterus: uncommon incidental finding. Gynecol Obstet. 2013;3:145.

7. Samal S, Samal SK, Begum J, Vaithy A. Lipoleiomyoma in a postmenopausal woman: an incidental finding. Int $\mathbf{J}$ Reprod Contracept Obstet Gynecol. 2015;4:508-10.

8. Maebayashi T, Imai K, Takekawa Y. Radiologic features of uterine lipoleiomyoma. J Comput Assist Tomogr. 2003;27:162-65.

9. Jagtap SV, Khatib WG, Jagtap SS, Kshirsagar NS. Large leiomyoma of the broad ligament. J Med Allied Sci. 2013;3(2):85-87.

10. Akyildiz EU, Ozuysal S, Arici A, Atalay MA. Pure uterine lipoma, a very rare benign tumour. Korean $\mathbf{J}$ Pathol. 2010;44:679-81.

11. Agarwal P, Prasad S, Chauhan DS, Rao ASN. Giant lipoleiomyoma-an intimidating entity: case report and literature review. Int J Reprod Contracept Obstet Gynecol. 2017;6:1660-3.

Cite this article as: Jagtap SV, Phalke A, Kshirsagar NS, Jagtap SS, Nasre N. Uterine Lipoleiomyoma: a rare variant of benign uterine neoplasm. Int J Reprod Contracept Obstet Gynecol 2019;8:2553-5. 